\title{
A study on the effect of performance based budgeting using activity based cost method
}

\author{
Rahmatollah Mohammadipour*
}

Department of accounting, Ilam Branch, Islamic Azad University, Ilam, Iran

\begin{tabular}{|c|c|}
\hline CHRON I CLE & A B S T RACT \\
\hline $\begin{array}{l}\text { Article history: } \\
\text { Received Feb } 25,2013 \\
\text { Received in revised format } \\
19 \text { September } 2013 \\
\text { Accepted } 23 \text { October } 2013 \\
\text { Available online } \\
\text { November } 182013\end{array}$ & $\begin{array}{l}\text { Nowadays, management of funds in different governmental organizations plays essential role in } \\
\text { accessing desirable objectives and in controlling operations efficiently and effectively. } \\
\text { Performance-based budgeting (PBB) is the practice of developing budgets based on the } \\
\text { relationship between planned funding levels and anticipated results from the plan. The } \\
\text { performance-based budgeting process is a technique where the administrators can apply to } \\
\text { manage more cost-efficient and effective budgeting programs. In this paper, we present an }\end{array}$ \\
\hline $\begin{array}{l}\text { Keywords: } \\
\text { Performance-based budgeting } \\
\text { PBB } \\
\text { Activity based cost } \\
\text { ABC method } \\
\text { Municipality }\end{array}$ & $\begin{array}{l}\text { empirical investigation to find out whether it is possible to apply PBB in various Iranian } \\
\text { municipalities or not. The proposed study detects different barriers in terms of strategy, } \\
\text { execution and monitoring through a questionnaire and investigations whether removing the } \\
\text { important trouble making issues could help management team apply PBB with an adaptation of } \\
\text { activity based cost method or net. The results indicate that management of some Iranian } \\
\text { municipalities could successfully implement PBB within organization when major barriers are } \\
\text { removed. }\end{array}$ \\
\hline
\end{tabular}

\section{Introduction}

Nowadays, management of funds in different governmental organizations plays essential role in accessing desirable objectives and in controlling operations efficiently and effectively. Performancebased budgeting (PBB) is the practice of developing budgets based on the relationship between planned funding levels and anticipated results from the plan. The performance-based budgeting process is a technique where the administrators can apply to manage more cost-efficient and effective budgeting programs. During the past few years, there have been different methods and techniques introduced for PBB implementation. Zamfirescu and Zamfirescu (2013), for instance, suggested goal programming techniques along with some decision support system as a strategy for PBB implementation. Kordbache (2007) provided necessary actions for successfully applying PBB in some Iranian organizations.

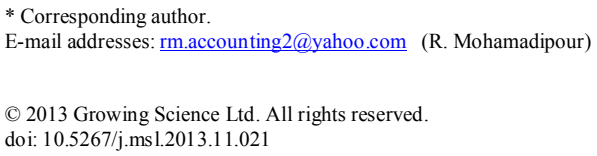


Melkers and Willoughby (1998) studied the trends toward improving performance in government and first discussed that past research on PBB in the states concentrates on anecdotal information and case analyses, usually including fewer than 10 states. Melkers and Willoughby (1998) provided national coverage of needs for PBB in the United States by surveying the 50 states concerning existing or planned legislation associated with performance-based budgeting as well as administrative necessities. They reviewed legislation and budget guidelines to detect their scope and focus and reported that all but three states had performance-based budgeting requirements, and most had established these requirements within the years of nineties. Thirty-one states had legislated performance-based budgeting to be conducted, while 16 states initiated this reform through budget guidelines or instructions. Thy also analyzed the foundations for executing PBB in the states.

Talebnia et al. (2012) examined the possibility of building PBB in Iran in terms of three perspectives including policymaking, implementing, and monitoring. There are different studies associated with the success of PBB implementation in various countries such as Thailand (Blöndal \& Kim, 2006), Finland (Blöndal et al., 2003), Singapour (Blöndal, 2006), Denmark (Blöndal, J.R., \& Ruffner, 2004), Australia (Blöndal \& Bergvall, 2007). Recently, budget decision-makers and the general public have requested better accountability for not just the use of resources, but for results that public programs create. As a result, the principles of PBB have become popular. PBB tries to deliver market-like data to the public sector and sends results to budget decision makers in the same way profits send investment indicators to financiers in the private sector. PBB injects necessary information on accomplishments into the resource allocation process.

\section{The proposed}

In this paper, we present an empirical investigation to find out whether it is possible to apply PBB in various Iranian municipalities or not. The proposed study detects different barriers in terms of policy making, execution and monitoring through a questionnaire and investigations whether removing the important trouble making issues could help management team apply PBB with an adaptation of activity based cost method or net. The population of the survey includes all experts who worked for different municipalities in west part of Iran in terms of budgeting planning, budgeting executives as well as deputies who are experts in budgeting planning. The sample size is calculated as follows,

$n=\frac{N \times z_{\alpha / 2}^{2} \times p \times q}{\varepsilon^{2} \times(N-1)+z_{\alpha / 2}^{2} \times p \times q}$,

where $N$ is the population size, $p=1-q$ represents the yes/no categories, $z_{\alpha / 2}$ is CDF of normal distribution and finally $\varepsilon$ is the error term. Since we have $p=0.5, z_{\alpha / 2}=1.96$ and $N=156$, the number of sample size is calculated as $n=60$. The sample size for three mentioned groups is proportion to their sub-group. In our survey the sample size for budgeting planning group is equal to $(60 / 312) \times 100 \approx 19$. In addition, the sample size for executive budgeting managers is $(60 / 312) \times 100 \approx 19$ and finally, the sample size of deputies is $(60 / 312) \times 112 \approx 22$. In our survey we have distributed 57 questionnaires and collected 50 fill ones. Cronbach alpha has been calculated as 0.81 , which is well above the minimum desirable level of 0.7 . There are four main hypotheses associated with the proposed study of this paper as follows,

1. It is possible to detect all barriers in terms of policy making.

2. It is possible to detect all barriers in terms of execution.

3. It is possible to detect all barriers in terms of monitoring.

4. Using activity based cost model integrated with PBB is the most suitable approach.

The questionnaire consists of 33 questions where 13 questions are associated with the first hypothesis and Table 1 demonstrates the results of our survey along with the responses, 
Table 1

The summary of the responses associated with the first hypothesis

\begin{tabular}{llccc}
\hline Item & Question & Prob. & Sig. & Result \\
\hline 1 & Lack of having a good strategy in macro level, & 0.90 & 0.001 & Confirmed \\
2 & Lack of having a good guidelines for executing budgets, & 0.84 & 0.018 & Confirmed \\
3 & Lack of having good performance measurement attributes, & 0.82 & 0.002 & Confirmed \\
4 & Lack of having accrual accounting instead of cash accounting, & 0.76 & 0.000 & Confirmed \\
5 & Lack of having managerial accounting system, & 0.96 & 0.001 & Confirmed \\
6 & Lack of familiarity with activity based cost method, & 1.000 & 000.0 & Confirmed \\
7 & Lack of having appropriate attributes for measuring municipality output, & 0.98 & 0.000 & Confirmed \\
8 & Different definition for municipality rules and regulations, & 0.96 & 0.003 & Confirmed \\
9 & Lack of having members of budgeting system in city management, & 0.90 & 0.002 & Confirmed \\
10 & Lack of believes in having good prediction for events in municipality, & 1.000 & 0.001 & Confirmed \\
11 & Weakness in internal rules and regulations, & 0.96 & 0.001 & Confirmed \\
12 & Lack of belief in having pragmatic systems, & 1.00 & 0.002 & Confirmed \\
13 & The culture of being responsive in the system. & 1.00 & 0.000 & Confirmed \\
\hline
\end{tabular}

As we can observe from the results of Table 1, the surveyed people mostly agreed on 13 different factors as major barriers to reach good PBB system in municipality. Therefore, the first hypothesis of this paper has been confirmed.

The second survey consists of factors in execution stage, which consists of 11 factors and Table 2 shows details of our findings,

Table 2

The summary of the responses associated with the second hypothesis

\begin{tabular}{llccc}
\hline Item & Question & Prob. & Sig. & Result \\
\hline 1 & Lack of having professional human resources, & 0.90 & 0.000 & Confirmed \\
2 & Low commitment to execute plans, & 0.92 & 0.000 & Confirmed \\
3 & Lack of familiarity of managers with managerial accounting, & 0.94 & 0.001 & Confirmed \\
4 & Resistance among managers for executing plans, & 0.98 & 0.000 & Confirmed \\
5 & Lack of having good payment and promotion plans, & 1.000 & 0.000 & Confirmed \\
6 & Lack of awareness on different resources and consumptions, & 1.000 & 0.001 & Confirmed \\
7 & Lack of familiarity of managers with PBB system, & 1.000 & 0.000 & Confirmed \\
8 & Lack of good familiarity with allocating cost to different tasks, & 0.92 & 0.000 & Confirmed \\
9 & Lack of having organizational structure, & 0.90 & 0.001 & Confirmed \\
10 & Lack of coordination between different groups of financial and operations, & 0.90 & 0.000 & Confirmed \\
11 & Lack of a good definition on various activities. & 0.92 & 0.001 & Confirmed \\
\hline
\end{tabular}

The results of Table 2 also indicate that all eleven factors have been confirmed as major barriers on executing PBB in the system.

The last part of the survey is associated with monitoring different factors associated with monitoring PBB implementation. In our survey, we have considered nine factors and the results of our investigation is summarized in Table 3 as follows,

\section{Table 3}

The summary of the responses associated with the third hypothesis

\begin{tabular}{llccc}
\hline Item & Question & Prob. & Sig. & Result \\
\hline 1 & Lack of attention to audit report, & 0.94 & 0.000 & Confirmed \\
2 & Lack of attention to supreme court of audit report, & 0.96 & 0.001 & Confirmed \\
3 & Necessity to consider to both supreme court of audit report and independent auditors, & 0.90 & 0.001 & Confirmed \\
4 & $\begin{array}{l}\text { Type of cooperation between the legislative and municipal agencies throughout the } \\
\text { country, }\end{array}$ & 1.000 & 0.000 & Confirmed \\
& Legal governmental requirements, & 1.000 & 0.001 & Confirmed \\
5 & Lack of adequate support from the municipal government and parliament, & 0.92 & 0.000 & Confirmed \\
6 & Lack of a clear definition of responsibilities and a timetable, & 0.98 & 0.001 & Confirmed \\
7 & Lack of institutional capacity, & 0.96 & 0.000 & Confirmed \\
8 & Lack of having proper system of reward and punishment. & 1.000 & 0.000 & Confirmed \\
\hline
\end{tabular}


The results of Table 3 also indicate that all nine components influence properly monitoring the PBB implementation.

\section{Conclusion}

In this paper, we have discussed that $\mathrm{PBB}$ is one of the most important parts of budgeting system and plays essential role for the success of any organization. The proposed model of this paper has implemented the method in some of municipalities in west part of Iran and tried to detect major barriers in three levels of policy making, execution and monitoring. In terms of policy makers, the study detected 13 major factors where lack of familiarity with activity based cost method, lack of believes in having good prediction for events in municipality and Lack of belief in having pragmatic systems. In terms of execution, the study detected 11 factors where lack of having good payment and promotion plans, lack of awareness on different resources and consumptions and lack of familiarity of managers with PBB system are considered as the most important barrier. Finally, in terms of monitoring the system, the study has detected 9 major barriers including type of cooperation between the legislative and municipal agencies throughout the country, legal governmental requirements and lack of having proper system of reward and punishment.

\section{Acknowledgement}

The authors would like to thank the anonymous referees for constructive comments on earlier version of this paper.

\section{References}

Blöndal, J.R., \& Kim, S.I. (2006). Budgeting in Thailand. OECD Journal on Budgeting, 5(3), 7-38. Blöndal, J.R., Kristensen, J.K., \& Ruffner, M. (2003). Budgeting in Finland. OECD Journal on Budgeting, 2(2), 119-155.

Blöndal, J.R. (2006). Budgeting in Singapore. OECD Journal on Budgeting, 6(1), 46-85.

Blöndal, J.R., \& Ruffner, M. (2004). Budgeting in Denmark. OECD Journal on Budgeting, 4(1), 5079.

Blöndal, J. R., \& Bergvall, D. (2007). Performance budgeting in Australia. OECD Journal on Budgeting, 7(3), 1-16.

Kordbache, M. (2007). Performance-based budgeting. The Journal of Planning and Budgeting, 11(6), 3-31.

Melkers, J., \& Willoughby, K. (1998). The state of the states: Performance-based budgeting requirements in 47 out of 50. Public Administration Review, 58(1), 66-73.

Talebnia, G., Vakilifard, H., Yeganeh, Y \& Mohammadipour, R. (2012). A comprehensive study on performance-based budgeting model: A case study of Iran's policy making, implementing and monitoring. Management Science Letters, 2(6), 2031-2040.

Zamfirescu, L., \& Zamfirescu, C.B. (2013). Goal programming as a decision model for performancebased budgeting. Procedia Computer Science, 17, 426-433. 